\title{
Distribution of members of the Anopheles gambiae complex in selected forested tourist areas of Cross River State, Nigeria.
}

\section{Authors:}

${ }^{*}$ Oduwole $\mathrm{OA}^{1}$,Oduola $\mathrm{AO}^{2}$, Oringanje $\mathrm{CM}^{3}$, Nwachuku $\mathrm{NS}^{4}$, Meremikwu $\mathrm{MM}^{5}$, UsehMF$^{6}$, Alaribe $\mathrm{AAA}^{6}$.

\section{Affiliation:}

${ }^{1}$ Department of Medical Laboratory Science, Achievers University, Owo, Nigeria, ${ }^{2}$ Department of Zoology, University of Ilorin, Nigeria

${ }^{3}$ Department of Entomology and Insect Science, University of Arizona, Tucson, USA

${ }^{4}$ Department of Public Health, College of Medical Sciences, University of Calabar, Nigeria,

${ }^{5}$ Department of Paediatrics, College of Medical Sciences, University of Calabar, Nigeria

${ }^{6}$ Department of Medical Laboratory Science, College of Medical Sciences, University of Calabar, Nigeria.

*Corresponding author: Email: olabisioduwole@yahoo.co.uk; Mobile: +2348056071976 


\section{Abstract}

Background: The Anopheles gambiae mosquitoes are the most abundant, efficient and widely distributed vectors of the malaria parasite in sub-Saharan Africa. In most African countries, where malaria control programmes are focused on the use of long-lasting insecticide treated bed net, there is need to evaluate the biting behaviour and the identity of such mosquitoes to determine the relevance and appropriateness of the control measure implemented.

Method: This study investigated the distribution and molecular characteristics of the Anopheles species in selected forested areas in Cross River State, Nigeria. Mosquitoes were collected using pyrethrum spray catch and Centre for Disease Control light traps modified with yeast and sugar to generate carbon dioxide $\left(\mathrm{CO}_{2}\right)$. Anopheles gambiae complex was identified using multiplex polymerase chain reaction followed by restriction fragment length polymorphism (PCR-RFLP) for molecular forms characterization.

Results: One hundred and four Anopheles gambiae s.l. were collected during the study. Multiplex PCR showed $75 \%$ of the species complex were A. gambiae s.s. and further characterization using PCR- RFLP showed that $53.8 \%$ of the A. gambiae s.l. identified were $A$. gambiae s.s.while $24.4 \%$ were A.coluzzii. The two species of the $A$. gambiae s.l. were found to be most abundant. The study also reported a $1.3 \%$ hybrid form of Anopheles gambiae s.s.and Anopheles coluzzii.

Conclusion: The findings suggest the first documented evidence of hybrid forms of $A$. gambiae s.s./A.coluzzii in South Eastern Nigeria although its epidemiological implication is still not clear. 
Key words: Vector, Anopheles gambiae; molecular forms, PCR, mosquitoes, malaria

\section{Background}

Although reports show a remarkable reduction in the prevalence of malaria in subSaharan Africa, millions of people are still at risk of the disease in this region [1-3]. In southern Nigeria, malaria is holoendemic and occurs throughout the year with the highest transmission occurring between April and October during the wet season [4].

The control of malaria in Nigeria revolves around an integrated process which emphasizes prompt accurate diagnosis and treatment and the use of anti-vector control measures. The utilization of Long-lasting Insecticide Treated Bed Nets (LLINs) is one of the strategies employed by the National Malaria Elimination Programme for vector control [5]. This strategy focuses mainly on mosquitoes that feed indoors neglecting the species that feed outdoors.

The major malaria vectors in Nigeria are the Anopheles gambiae complex where in $A$. gambiae s.s and $A$. arabiensis are the most dominant sibling species, also the Anopheles funestus group [6-7]. These are widely distributed across Nigeria, covering the mangrove and coastal areas of the south, Guinea savannah in the middle belt to the Sahel savannah of the northern part of the country. Anopheles gambiae and $A$. arabiensis prefer to breed in an environment that is sunlit and has shallow temporary pockets of fresh water such as, puddles, pools and hoof prints and water collected in car tyre tracks [8]. In Nigeria, Anopheles gambiae s.s. has been reported to have an affinity for human blood (anthropophagic) and rests indoors (endophilic) with sporozoite rates ranging from 0.2 to $11.8 \%$ [8]. In contrast, $A$. arabiensis has sporozoites rates of 0 to $4.8 \%$ and has been confirmed to have a preference for animal blood, feeding on 
humans in the absence of animals and resting outdoors (exophilic) [8]. The range and relative abundance of $A$. gambiae s.s. and $A$. arabiensis appear to be strongly influenced by climatic factors, such as total annual rainfall [9] .A. gambiae s.s.is prevalent in forested zones in contrast to $A$. arabiensis which is predominant in several Sudan Sahel and northern Guinea savannahs [10-11]. Generally, A.arabiensis tends to predominate in arid savannas, whereas A.gambiae is the dominant species in humid forest zones [12]. Where the two appear in sympatry, large changes in species composition often occur with $A$.arabiensis predominating during the dry season and $A$. gambiae becoming more abundant during the rainy season [11].

Anopheles gambiae s.s. is divided into five chromosomal forms as a result of a paracentric inversion on chromosome two [13-14]. In addition to the chromosomal differentiation, A. gambiae s.s was differentiated molecularly based on the sequence differences in the "intergenic spacer" (IGS) of the rDNA that is on the ' $\mathrm{X}$ ' chromosome into 'S' and 'M' molecular forms [15]. Few years ago, a study reported that $A$. gambiae ' $M$ ' form is another species and not a genetic variation of $A$. gambiae s.s.and is now widely accepted internationally [16]. Thus, while the ' $S$ ' form retains the name $A$. gambiae s.s., the 'M' form is now known as $A$. coluzzii. It has been reported that $A$. gambiae s.s.and $A$. coluzzii exists in sympatry in West Africa. Studies in Lagos, South Western Nigeria which lies in the forest ecological zone of Nigeria [17-18] and Kano, Northern Nigeria in Savannah ecological zone of Nigeria [19] showed that $A$. coluzzii is more abundant than $A$. gambiae. However, this is in contrast with the previous report from a wider surveillance which showed that the molecular $\mathrm{S}$ form (now known as $A$. gambiae) is predominant and has a wider distribution across Nigeria compared to $A$. 
coluzzii [7-20] .Hybridization of the two species is rarely reported to occur, however,the hybrid form was recently reported in Nigeria by two studies from South Western Nigeria [21] and North Central Nigeria [22] respectively. The rainforest belt of Nigeria where Cross River State (CRS) is located has a fairly large population of very rare wildlife. The state shares a long border with Cameroon to form a protected ecological zone and it is recognized by United Nations Educational, Scientific and Cultural Organisation (UNESCO) as a world heritage centre. The forests host up to 16 species of primates. These include Chimpanzees, Drill monkeys, potty-nosed monkeys, Mangabey monkeys, Preuss's Guenon and many others [23-25]. Cross River state has an estimated population of over three million eight hundred thousand people and is a major tourist destination in Nigeria because of its rare eco-tourism. Some of these forests are located in Akamkpa and Boki Local government areas of CRS. Villagers living close to the forests also hunt the animals for food and go to the forests for logs; in addition, forest rangers live in some part of the forests to protect the animals.

There is a paucity of information on the identity of members of the Anopheles gambiae complex in forested communities that border the wildlife sanctuaries in South Eastern Nigeria, which is usually in the print for malaria for unprotected immune and nonimmune foreign tourists. In addition to the threat of zoonotic diseases to tourists and humans living in these forested communities, it is expedient to evaluate the current malaria vectors driving malaria distribution in forest communities that are conserved for endangered non- human primates and other wildlife in Cross River State.

\section{Materials and Methods}




\section{Study area}

This study was carried out in forested areas and border communities of Cross River State, South Eastern Nigeria. Cross River State has an estimated population of about $3,800,000$ million people who are mostly farmers.

Mosquitoes were collected in the following locations; Bonchor, Drill Ranch in Afi Mountain Wildlife Sanctuary (Latitude $6.2999^{\circ}$ and Longitude $8.9977^{\circ}$, Altitude $300 \mathrm{~m}$ ), Cross River National Park (Latitude $5.2130^{\circ}$, Longitude $8.2548^{\circ}$, Altitude 143), Obung (Latitude 5.3458, Longitude 8.39445) Aking/Osunba(Latitude 5.4334 Longitude 8.6370 Altitude 182.6), Iko-Esai and Rhoko forest, (Latitude 4.9714 Longitude 8.3216 Altitude 135m)(Figure . 1), and Calabar municipal, (Latitude $4.977^{\circ}$, Longitude $8.334^{\circ}$, Altitude 135m). Calabar Municipal was the only urban setting in the study area, and was included because of the two wildlife sanctuaries (CERCOPAN and Pandrillus) located in the town. The average annual rainfall measurement during the study period was about 2,863.5mm (obtained from CERCOPAN and Pandrillus, Nigeria). Villages were selected if they were close to wildlife reserves.

\section{Sample collection}

Mosquitoes were collected using CDC light-traps and CDC ultraviolet light traps (Model 1312 and 912, manufactured by John W. Hock Company, Gainesville, Florida, U.S.A) modified with yeast and sugarto generate $\mathrm{CO}_{2}$ as described by Obenauer et al. [27] and synthetic lure (BG- Lure ${ }^{\mathrm{TM}}$ Biogents $\AA$, Regensburg). This was to enhance the attraction of the Anopheles to the light traps [27]. The CDC mosquito traps were set at different locations such as outdoors nearslow-flowing rivers or streams in the border communities and forests, outdoor close to human dwellings, and inside rooms where 
humans sleep under insecticide treated nets (ITNs). Six traps were set up near slowflowing streams for three consecutive days in each community and six in the nearby forest. Communities with wildlife sanctuary were selected as forest locations. Each trap was about $15 \mathrm{~m}$ from the other, following the method described in another study [27]. All traps were covered with a large black cover supplied with the traps to protect the trap from rain (Supplementary Figure 1). Six traps were also set up outside human dwellings about $15 \mathrm{~m}$ away from living quarters, and in rooms where occupants sleep under ITNs. This is because the mosquitoes may not be attracted to the traps if they can bite humans. The mosquitoes were collected all night for three consecutive days monthly from 1800hours to 0600hours over a period of 12 months from April 2013 to June 2014 In addition, pyrethrum indoor spray catch was conducted from April 2013 to June 2014, in an average of 8 houses per study area perday between 0600hours and 0700hours for three consecutive days to cover dry (December to March) and rainy seasons (April to November). The knocked down mosquitoes were collected and kept in Eppendorf tubes in which silica gel had been added and plugged with cotton balls. Mosquitoes collected with the CDC traps were killed by keeping them in the $-20^{\circ} \mathrm{C}$ freezer for two hours. For remote study locations without electricity, the traps were kept in bags already sprayed with insecticide. The female mosquitoes were later sorted out into different species and stored in an Eppendorf tube containing silica gel and plugged with cotton wool for further confirmation.

\section{Laboratory procedures}

\section{Morphological identification}


Anopheline mosquitoes were separated from other genera of mosquitoes based on the characteristics of their maxillary palps. Also, males were differentiated from the females using their antennae, which are plumose for males and pilose for the females [28]. Furthermore, the female Anopheles mosquitoes were identified using well described morphological identification key [29-30]. After morphological identification, head and thoraces of the Anopheles were removed with a scalpel blade and examined for sporozoites using enzyme-linked immunosorbent assay technique as described by Obenauer et al. [27].

\section{DNA Extraction}

Deoxyribonucleic Acid (DNA) was extracted from individual $A$. gambiae placed in a $2 \mathrm{ml}$ Eppendorf tube using a QIAamp DNA mini kit (Qiagen). The individual mosquito was ground using plastic pestle. DNA extraction was completed following the manufacturer's protocol. Eluted DNA was frozen at $-20^{\circ} \mathrm{C}$ for further molecular analysis.

\section{Mosquito species genotyping}

Species identification was based on species-specific fixed differences in the rDNA region, including $28 \mathrm{~S}$ coding region and intergenic spacer (IGS) region. DNA extracted from legs and wings of mosquitoes were subjected to species specific PCR assays following the procedure of Scott et al.[31]. Laboratory strains of the Anopheline species provided were used as positive controls. PCR products were visualized under UV light following gel electrophoresis. Positive amplicons for A. gambiae s.s were further digested to give rise to molecular forms $\mathrm{S}$ (formerly $A$. gambiae) and $\mathrm{M}$ (formerly $A$. coluzzii) using Restriction Fragment Length Polymorphism (RFLP) [32]. The result was analyzed by using $2 \%$ agarose gel electrophoresis and GelRed staining. 


\section{Statistical Analysis}

Z- test, and Chi-square test were used to determine differences between $A$. gambiae s.s. ( $\mathrm{S}$ form) and $A$. coluzzii ( $\mathrm{M}$ form) and their association with variables such as season of the year, location (indoor or outdoor) and geographical area. .

\section{Results}

\section{Distribution of mosquito species in the study area}

Data were obtained from the following study locations; Cross River National Park (CRNP), Obung, Osunba, Aking, Rhoko forest,and Iko-Esai in Akampka; Drill Ranch (Afi mountain wildlife sanctuary) and Bonchor in Boki and Calabar municipality. One thousand, one hundred and eighty-two (1182) mosquitoes comprising 10 known species from 7 genera were trapped between April 2013 and June 2014 using different trapping methods including pyrethrum indoor spray catch. Forty of these mosquitoes were caught using human bait catch. The measurement recorded in June 2013, was 403mm compared to $287 \mathrm{~mm}$ recorded in June 2014 (Table 1). It was observed that fewer mosquitoes were collected during the heavy precipitation. In June 2013, the lowest distribution of $4 \%$ was recorded during the whole study as against the $23 \%$ collected in June 2014 which was the highest collection made during the period. 


\section{Table 1: Rainfall measurement during data collection and number of mosquitoes trapped}

\begin{tabular}{lll}
\hline $\begin{array}{c}\text { Month of collection } \\
\text { (April 2013-June 2014) }\end{array}$ & $\begin{array}{c}\text { Rainfall } \\
\text { measurement } \\
(\mathrm{mm})\end{array}$ & $\begin{array}{c}\text { No. of Mosquitoes } \\
\text { Trapped (\%) }\end{array}$ \\
\hline April & 181.1 & $23(2 \%)$ \\
\hline June & 405.1 & $46(4 \%)$ \\
July & 507.8 & $12(1 \%)$ \\
August & 218.5 & $15(1 \%)$ \\
September & 544.5 & $46(4 \%)$ \\
October & 450.6 & $112(10 \%)$ \\
December & 148.8 & $63(5 \%)$ \\
January & 15 & $61(5 \%)$ \\
March & 81.1 & $19(2 \%)$ \\
April & 230.1 & $92(8 \%)$ \\
May & 349.6 & $418(35 \%)$ \\
\hline June & 287.2 & $275(23 \%)$ \\
\hline Total & 2563.8 & $1182(100 \%)$ \\
\hline
\end{tabular}


As expected, the number of mosquitoes collected in the wet season [1039 (88\%)] was significantly higher than the mosquitoes collected in the dry season $143(12 \%)$ $(P<0.0002)$ Figure 2 shows a similar observation for the female mosquitoes collected for the study.

Seven hundred and seventy (770) of the mosquitoes were females, out of which 104 (13.5\%) were Anopheles species. Other species were Culex species (54.4\%), Uranotaenia species (13.3\%), Aedes species (4.7\%), Mansonia species (0.7\%), Lutzia species (0.1\%), Coquillettidia species (0.1\%), while $13.1 \%$ could not be identified because they had become overgrown with fungi.Culex species were significantly more abundant than other species followed by Anopheles species $(P<0.0001)$. Rhoko forest had the highest proportion of female mosquitoes (22\%), National park had19\%, Calabar had18\%, Obung had 17\% and Bonchor recorded the least 3\% (Figure 3a)Obung had the highest proportion of female Anopheles mosquitoes (40\%), followed by National park (30\%) and Rhoko forest had the least proportion of female Anopheles mosquitoes(1.8\%) (Figure 3b).

Mophological identification shows that A.gambiae s.I. made up about $97 \%$ of the Anopheles species and $2.9 \%$ were $A$. rufipes. Among the identified A. gambiae s.l, $77 \%$ were $A$. gambiae s.s $(\mathrm{P}=0.0012)$; the remaining $23 \%$ could not be identified because of contamination caused by fungi (Supplementary Table 1). 
A. gambiae s.s samples were further classified into their molecular forms usingPCR-RFLP. Forty-two (53.8\%) were identified as S form (A. gambiae s.S) and 19 (24.4\%) were identified as $M$ form $(A$. coluzzii) $(Z=-6.1293$, $P$-value $<0.0001)$. Sixteen of the mosquitoes $(20.5 \%)$ had no specific band and could not be classified into molecular forms, while $1(1.3 \%)$ was a hybrid form(S/M) (Figure 4).

Overall, there was a higher distribution of Anopheles species in the border communities than the forests and more were caught indoors than outdoors of human dwellings within the communities. Also, for traps set outdoors, we collected more Anopheles species near slow-flowing streams than other locations outdoor. The mean number of the different genus of mosquitoes collected over the study period is represented in (Table 2). Analysis demonstrated a significant difference according to trap location. Mean distribution of Anopheles species, Culex species. $\quad(p<0.001)$ and other species $(p=0.003)$ were significantly caught indoors than by the slow-flowing stream. Additionally, more Anopheles species $(p<0.001)$, Culex species $(p<0.001)$, Aedes species $(p=0.002)$ and other species $(p<0.001)$ were significantly caught outdoor of human dwellings than by the streams (Table 2). A similar capture trend was observed for the total mean number of mosquitoes irrespective of genus classification. 
Table 2 : Differences in the number (mean \pm SD) of mosquito genus caught by trap location in 2013 2014 in selected forested tourist areas of Cross River State, Nigeria.

\begin{tabular}{|c|c|c|c|c|c|}
\hline \multirow[b]{2}{*}{ Genus } & \multicolumn{5}{|c|}{ Trap location } \\
\hline & Stream & Indoor & Outdoor & $\mathrm{F}$ & $p$-value \\
\hline Aedes $(n=45)$ & $1.40 \pm 0.30$ & $1.75 \pm 0.03$ & $2.11 \pm 0.22$ & 12.27 & $0.002^{*}$ \\
\hline $\begin{array}{l}\text { (Row mean-col mean), p-value } \\
\text { Stream }\end{array}$ & - & - & - & & \\
\hline Indoor & $(0.35), 0.237$ & - & - & & \\
\hline Outdoor & $(0.71), 0.002$ & $(0.36), 0.093$ & - & & \\
\hline $\begin{array}{l}\text { Anopheles ( } n=104) \\
\text { (Row mean-Col mean), p-value }\end{array}$ & $1.33 \pm \overline{0.34}$ & $1.77 \pm 0.05$ & $2.05 \pm 0.15$ & 26.78 & $\varangle 0.001^{*}$ \\
\hline Stream & - & - & - & & \\
\hline Indoor & $(0.44), \unlhd 0.001$ & - & - & & \\
\hline Outdoor & $(0.72), \overline{\triangleleft 0.001}$ & $(0.28), 0.056$ & - & & \\
\hline $\begin{array}{l}\text { Culex ( } n=424) \\
\text { (Row mean-Col mean), } p \text {-value }\end{array}$ & $1.31 \pm 0.23$ & $1.75 \pm 0.06$ & $2.02 \pm 0.11$ & 80.23 & $\varangle 0.001 *$ \\
\hline Stream & - & - & - & & \\
\hline Indoor & $(0.44), \unlhd 0.001$ & - & - & & \\
\hline Outdoor & $(0.71), ₫ 0.001$ & $(0.26), \underline{0.003}$ & - & & \\
\hline $\begin{array}{l}\text { Unknown ( } n=373 \text { ) } \\
\text { (Row mean-Col mean), p-value }\end{array}$ & $1.27 \pm 0.25$ & $1.76 \pm 0.06$ & $2.07 \pm 0.19$ & 53.82 & $\varangle 0.001^{*}$ \\
\hline Stream & - & - & - & & \\
\hline Indoor & $(0.49), \unlhd 0.001$ & - & - & & \\
\hline Outdoor & $(0.80), \unlhd 0.001$ & $(0.31), \underline{0.024}$ & - & & \\
\hline $\begin{array}{l}\text { ** Other }(\mathrm{n}=175) \\
\text { (Row mean-Col mean), } \mathrm{p} \text {-value }\end{array}$ & $1.31 \pm 0.23$ & $1.75 \pm 0.06$ & $2.01 \pm 0.12$ & 53.42 & $\varangle 0.001 *$ \\
\hline Stream & - & - & - & & \\
\hline Indoor & $(0.44), \underline{0.003}$ & - & - & & \\
\hline Outdoor & $(0.70),<0.001$ & $(0.26), 0.171$ & - & & \\
\hline $\begin{array}{l}* * * \text { Total mosquitoes } \\
(\mathrm{n}=1,121)\end{array}$ & $1.30 \pm 0.25$ & $1.76 \pm 0.06$ & $2.05 \pm 0.16$ & 269.15 & $\varangle 0.001 *$ \\
\hline (Row mean-Col mean), p-value & 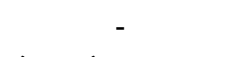 & - & - & & \\
\hline Stream & $(0.46), \unlhd 0.001$ & - & - & & \\
\hline $\begin{array}{l}\text { Indoor } \\
\text { Outdoor }\end{array}$ & $(0.75), \unlhd 0.001$ & $(0.29), \unlhd 0.001$ & - & & \\
\hline
\end{tabular}

\#Lutzia genus was excluded in the analysis because of few observed number (only one mosquito was caught)

*Significant p-value using one-way ANOVA test. Underlined p-values were significant after a post hoc Bonferroni test

** Aedes, Mansonia, Uranotaenia species

*** * Forty mosquitoes collected by human bait were not included in the analysis

\section{Discussion}


A higher collection of mosquitoes was observed in the wet season, during which one thousand, and thirty nine mosquitoes (88\%) were collected, compared to $143(12 \%)$ in the dry season. This observation was similar to findings from other study areas [33]. Anopheles abundance and malaria transmission is usually characterized and dependent on rainfall in Nigeria as this marks the availability of breeding sites [33]. This is probably because Anopheles gambiae s.l.is known to have a preference for clear water sources as their breeding grounds [28], which are readily available during the rainy season. The highest mosquito distribution was observed in June 2014 in contrast to the lowest in June 2013. This is may be due to the heavy rainfall recorded in June 2013, which was about twice of the measurement of rainfall in June 2014. It is believed that excess rainfall can wash away the mosquitoes' breeding sites [34].

Morphological identification of the Anopheles species showed that $A$. gambiae s.I. and A. rufipes were the two Anopheles species identified. While $A$. rufipes is not a major vector of malaria, it has been implicated in some recent studies as a secondary vector of malaria [35]. This study also showed that $A$. gambiae s.s was significantly more abundant than A.coluzzii. This is similar to results from other parts of Nigeria [7, 20] showing that $A$. gambiae s.s.is a predominant and widely distributed species, especially in Southern Nigeria compared to the A.coluzzii.

In addition, this study found a hybrid form of $A$. gambiaes.s./A.coluzzii, which agrees with the findings from two recent studies [22]. The findings from our study and the previous reports showed that the hybridization of $A$. gambiaes.s./A.coluzzii is still rare with these two studies [21-22] reporting its occurrence in Nigeria at a low prevalence that ranges between $0.5 \%-0.8 \%$. Although, the epidemiological implication of the 
hybrid form to malaria control is still unclear, it should be a cause for concern because of the possible transference of "knock down resistant gene" (kdr gene) from A. gambiae to A.coluzzii [32, 36-37].

As expected, more Anopheles gambiae species were found in the border communities compared to the forest locations but the difference was not significant. However, it was observed that a high proportion of the A. gambiae s.s. caught in this study were from the CRNP even though it is located in the forest. The CRNP has sleeping quarters built for rangers and tourists with wide open spaces which harbor pockets of water from rainfall and human activities. On the contrary, while tourists were allowed to visit the Drill Ranch and Rhoko forests, human activities that involved alteration of the forests in any form were discouraged. It is believed that small collections of water from rainfall and human activities will encourage $A$. gambiaes.s. to breed, in addition to the availability of blood meals from humans $[6,21,38]$. This was evident in the distribution of $A$. gambiae s.s in CRNP at $40 \%$ compared to $4 \%$ caught at Drill Ranch and none from Rhoko forest.

It was observed that in sites around human dwellings (outdoors and indoors), there were greater numbers of Anopheles mosquitoes collected than by the stream. This may be because most of the Anopheles species are A.gambiae and A.coluzzi, which are naturally attracted to human dwelling. Additionally, the Anopheles species collected outdoors were higher than the mosquitoes collected indoor but the difference was not statistically significant. It has been widely reported that $A$. gambiae is a species that is notorious for feeding and resting indoors [37]. The marginal decrease in the number of mosquitoes collected indoors compared to outdoors could be as a result of the malaria control programme, which is targeted only at indoor resting and biting mosquitoes 
resulting in a shift in behavior. There have been evidence on changes in biting and resting behavior of malaria vectors as a result of bed-net usage [39]. With $77 \%$ of the Anopheles species identified as A.gambiae s.slt is important to state that the presence of Anopheles species outdoor also has serious consequences for malaria control programme in the study area, since the main malaria control intervention involves the indoor use of LLINs. Tourists and residents enjoying outdoor evening time around this location may have to resort to the use of other alternatives such as repellents or wearing long clothing to protect themselves from mosquito bites. In addition, high levels of outdoor biting by $A$. gambiae s.s. have also been reported in a study in Equatorial Guinea [40]. This may corresponds to outdoor human activities in the early evening, however data on this was not collected.

This study did not detect the presence of $A$. arabiensis. This could be because $A$. arabiensis is predominantly found in arid environments and in areas where deforestation and urbanization have taken place $[9,20]$. In addition, there is a possibility of existence of $A$. arabiensis in the $25 \%$ unidentified A.gambiae complex. Furthermore, it is possible that the type of traps and where they were located could have played a major role in the number of mosquitoes caught during this study.

This study did not detect malaria infection in any of the malaria vectors identified. This may indicate to a certain extent that the malaria control strategies have been effective in creating a barrier between the mosquitoes and the hosts. The detection of infected Anopheles mosquitoes could also have been missed if the malaria parasites were still at the oocyst stage. This is in tandem with the observation in Oduwole et al. [26]. The 
report of the study showed that the prevalence of malaria among adults screened was low at $9.8 \%$ compared to the national average which is put at $27 \%$ by the WHO [41].

The high distribution of other species of mosquitoes such as Culex in large proportion should also be worrisome because of their ability to transmit neglected tropical diseases such as the lymphatic filariasis which is prevalent in Cross River State, Nigeria [42-45] In addition, Aedes species was about $5 \%$ of the mosquitoes collected during the study. This should be a source of concern because of its capacity to transmit yellow fever, a re-emerging viral haemorrhagic disease in Nigeria [3]. This study shows that tourists frequenting the forests and people living around non-human primates may not be at risk of simian malaria as observed in other studies [27, 46].

\section{Conclusion}

Anopheles gambiae and $A$. coluzzii may be responsible for malaria transmission in the forest border between Cross River State and Cameroon but the existence of $A$. rufipe should not be taken for granted as secondary vector may constitute a nuisance in certain conditions. Additionally, hybridization of A.gambiae and A. coluzzii is still rare. Our study reported a prevalence of $1.3 \%$ that is not far from the range reported in previous studies from Nigeria and it is the first report from South Eastern Nigeria.

It is propose that tourists visiting these forests should wear protective clothing and use insect repellant during the day and sleep under LLIN at night to prevent malaria infection and other vector-borne diseases.

It is also recommended that future studies should investigate human behavior in the study area and how humans interact with the mosquito vectors. 


\section{Study limitation:}

The main study limitation is that there were not many traps available per study site due to limited resources. This may have contributed to the low number of mosquitoes caught during the study.

\section{Authors' contributions}

OOA conceived the study. OOA, AAA and UMF designed the study. Laboratory investigation was supervised by OOA and NNS. Data collection was supervised by OOA and NNS and was interpreted by OOA, OAO, CO. OOA and MMM wrote the first draft of the manuscript. All authors criticallyappraised and approved the final draft of the manuscript.

\section{Compliance with ethical standards}

. Not applicable.

Consent for publication: Not applicable.

Availability of data and materials: The data sets generated during the current study are available from the corresponding author on reasonable request.

Conflict of interest: The authors declare that they have no competing interests.

Abbreviations: Cross River State (CRS), Restriction fragment length polymorphism (PCR-RFLP), World Health Organization (WHO), Long Lasting Insecticide Treated Bed Net (LLIN), intergenic spacer (IGS), Cross River National Park (CRNP), Centre for Disease Control (CDC), Centre for Disease Control Ultraviolet (CDC UV), Species 
(Spp).Deoxyribonucleic Acid (DNA), Naval Medical Research Unit number -3 (NAMRU -

3)

\section{Acknowledgements}

This study was supported in part by theTertiary Education Trust Fund (TETFUND) and US-Naval Medical Research Unit Number-3 (NAMRU-3). We would like to thank Friday O. Odey for assisting with the field work, Iwara Arikpo and Okoro Anthony for data analysis, Nahmy Fahmy and Mba Mosore for assisting with the laboratory investigations. We also wish to acknowledge the Pandrillus Foundation and CERCOPAN Nigeria for giving us access to their wildlifesanctuaries during data collection.

\section{References}

1.Alho RM, Machado KV, Val FF, Fraiji NA, Alexandre MA, Melo GC. Alternative transmission routes in the malaria elimination era: an overview of transfusiontransmitted malaria in the Americas. Malaria journal. 2017; 16(1):78.

https://malariajournal.biomedcentral.com/articles/10.1186/s12936-017-1726-y

2. WHO, 2013, WHO. Factsheet on the world malaria report.

https://www.who.int/malaria/media/world_malaria_report_2013/en/

3. World Malaria Report. World Malaria Report 2017. Retrieved July 24, 2018, from http://www.who.int/malaria/publications/world-malaria-report-2017/report/en/ 
4. Chukwuocha UM, Dozie IN. Malaria transmission and morbidity patterns in holoendemic areas of Imo River Basin of Nigeria. BMC research notes. 2011; 4(1):514. https://bmcresnotes.biomedcentral.com/articles/10.1186/1756-0500-4-514

5. National Population Commission, National Malaria Control Programme and ICF International. Nigeria Malaria Indicator Survey 2010. Ref. NGA_2010_MIS_v01_M. Dataset downloaded from http://catalog.insn.org/index.php/catalog/4135 on May 13. 2019

6. Awolola TS, Okwa O, Hunt RH, Ogunrinade AF, Coetzee M. Dynamics of the malaria-vector populations in coastal Lagos, south-western Nigeria. Annals of Tropical Medicine \& Parasitology. 2002; 96(1):75-82.

https://www.ncbi.nlm.nih.gov/pubmed/11989536

7. Awolola TS, Oyewole IO, Amajoh CN, Idowu ET, Ajayi MB, Oduola A, et al. Distribution of the molecular forms of Anopheles gambiae and pyrethroid knock down resistance gene in Nigeria. Acta tropica. 2005; 95(3):204-9.

https://www.sciencedirect.com/science/article/abs/pii/S0001706X05001476

8. Federal Ministry of Health, Federal Republic of Nigeria. National Malaria Strategic Plan 2014-2020. Abuja: Federal Ministry of Health, Federal Republic of Nigeria Retrieved from

http://www.nationalplanningcycles.org/sites/default/files/planning_cycle_repository/nigeri a/nigeria_national_malaria_strategic_plan.pdf. Access August 2018

9. Lindsay SW, Parson L, Thomas CJ. Mapping the range and relative abundance of the two principal African malaria vectors, Anopheles gambiae sensu stricto and An. arabiensis, using climate data. Proceedings of the Royal Society of London. Series B: Biological Sciences. 1998; 265(1399):847-54.

https://royalsocietypublishing.org/doi/abs/10.1098/rspb.1998.0369 
10. Coluzzi M, Sabatini A, Petrarca V, Di Deco MA. Chromosomal differentiation and adaptation to human environments in the Anopheles gambiae complex. Tran $\mathrm{R}$ Soc Trop Med Hyg, 1979; 73: 483-497. https://doi.org/10.1016/0035-9203(79)90036-1

11. Onyabe DY, Conn JE. Population genetic structure of the malaria mosquito Anopheles arabiensis across Nigeria suggests range expansion. Molecular Ecology. 2001;10(11):2577- https://onlinelibrary.wiley.com/doi/full/10.1046/j.09621083.2001.01387.x

12. Coetzee M, Craig M, Le Sueur D. Distribution of African malaria mosquitoes belonging to the Anopheles gambiae complex. Parasitology today. 2000;16(2):74-7. https://www.sciencedirect.com/science/article/pii/S016947589901563X

13. Coluzzi M, Petrarca V, \& di Deco MA. Chromosomal inversion intergradation and incipient speciation in Anopheles gambiae. Italian Journal of Zoology, 1985; 52(1-2), 4563. https://www.tandfonline.com/doi/abs/10.1080/11250008509440343

14. Toure YT, Dolo G, Petrarca V, Traore SF, Boure M, Dao A, Carnahan J, Taylor, CE. Mark-release-recapture experiments with Anopheles gambiae s.l. in Banambani Village, Mali, to determine population size and structure. Med Vet Entomol, 1998; 12: 74-83. https://www.ncbi.nlm.nih.gov/pubmed/9513942

15. della Torre A, Fanello C, Akogbeto M, Dossou-yovo J, Favia G, Petrarca V, Coluzzi M. Molecular evidence of incipient speciation within Anopheles gambiae s.s. in West Africa Insect Mol Biol. 2001;10(1):9-18. https://doi.org/10.1046/j.13652583.2001.00235.

16. Coetzee M1, Hunt RH, Wilkerson R, Della Torre A, Coulibaly MB, Besansky NJ. Anopheles coluzzii and Anopheles amharicus, new members of the Anopheles gambiae complex. Zootaxa. 2013;3619:246-74. https://www.ncbi.nlm.nih.gov/pubmed/26131476 
17. Oduola AO, Idowu ET, Oyebola MK., Adeogun AO, Olojede JB, Otubanjo OA, et al. Evidence of carbamate resistance in urban populations of Anopheles gambiae s.s. mosquitoes resistant to DDT and deltamethrin insecticides in Lagos, South-Western Nigeria. Parasites \& Vectors, 2012; 5, 116-116. doi: 10.1186/1756-3305-5-116. https://parasitesandvectors.biomedcentral.com/articles/10.1186/1756-3305-5-116

18. Oduola AO, Obansa JB, Ashiegbu CO, Adeogun A, Otubanjo OA, Awolola TS. High level of DDT resistance in the malaria mosquito: Anopheles gambiae s.l. from rural, semi urban and urban communities in Nigeria. Journal of Rural and Tropical Public Health, 2010; 9, 114-120. jrtph.jcu.edu.au/vol/JRTPH_vol9_p114-

120_Oduola.pdf

19. Ibrahim SS, Manu YA, Tukur Z, Irving H, Wondji CS. High frequency of kdr L1014F is associated with pyrethroid resistance in Anopheles coluzzii in Sudan savannah of northern Nigeria. BMC Infectious Diseases, 2014; 14(1), 441. doi: 10.1186/1471-2334-14-441

20. Onyabe, DY, Vajime, CG, Nock, IH, Ndams, IS, Akpa, AU, Alaribe, AA, et al. The distribution of $\mathrm{M}$ and $\mathrm{S}$ molecular forms of Anopheles gambiae in Nigeria. Transactions of the Royal Society of Tropical Medicine and Hygiene, 2003; 97(5), 605-608.

21. Okorie PN, Ademowo OG, Irving H, Kelly H, Louise A, Wondji CS. Insecticide susceptibility of Anopheles coluzzii and Anopheles gambiae mosquitoes in Ibadan, Southwest Nigeria. Medical and veterinary entomology, 2015; 29(1), 44-50.

22. Aju-Ameh OC, Awolola TS, Mwansat GS, Mafuyai HB. Molecular Identification, Species Composition and Distribution Maps of Malaria Vector Species in Selected Communities in Benue State, North Central Nigeria. IOSR Journal of Biotechnology and Biochemistry (IOSR-JBB) ISSN: 2455-264X,3(2), 2017; 1-9. www.iosrjournals.org/iosr jbb/papers/Volume\%203,\%20Issue\%202/A03020109.pd

23. Gadsby EL, Feistner ATC, Jenkins Jr, PD. Coordinating conservation for the drill (Mandrillus leucophaeus): Endangered in forest and zoo. In: Olney P.J.S., Mace G.M., Feistner A.T.C. (eds) Creative Conservation, 1994; (pp. 439-454). Springer, Dordrecht. https://link.springer.com/chapter/10.1007/978-94-011-0721-1_26\#citeas

24. Mills W, Cress D, Rosen N. Pan African Sanctuary Alliance (PASA) 2005 Workshop Report. Conservation Breeding Specialist Group (SSC/IUCN), Apple Valley, 
MN, 104.

www.cpsg.org/sites/cbsg.org/files/documents/PASA\%202005\%20final\%20report.pdf

25. Kormos R, Boesch C, Bakarr MI, Butynski TM. West African chimpanzees: status survey and conservation action plan: International Union for Conservation of Nature and Natural Resources. https://portals.iucn.org/library/sites/library/files/documents/2003059.pdf

26. Oduwole OA, Arikpo II, Esu EB, Udoh EE, Bello S, Odey FA, et al. Molecular Investigation of Simian Malaria among People in Frequent Contact with Non-human Primates in Forest Areas of Cross River State, Nigeria: A Cross Sectional Study. Calabar Journal of Health Sciences, 2017; 1(1), 42-50.

cjhs.unical.edu.ng/published/Olabisi_n_Co.pdf

27. Obenauer PJ, Abdel-Dayem MS, Stoops CA, Villinski JT, Tageldin R, Fahmy NT, et al. Field responses of Anopheles gambiae complex (Diptera: Culicidae) in Liberia using yeast-generated carbon dioxide and synthetic lure-baited light traps. Journal of medical entomology, 2013; 50(4), 863-870. https://doi.org/10.1603/ME12174

28. Service MW. Studies on sampling larval populations of the Anopheles gambiae complex. Bulletin of the World Health Organization. 1971;45(2):169.

https://www.ncbi.nIm.nih.gov/pmc/articles/PMC2427901/

29. Gillies MT \& Coetzee M. A supplement to the Anophelinae of Africa South of the Sahara. Johannesburg, South Africa: Publication no. 55. The South African Institute for Medical Research. Johannesburg, 1987; 143 pp https://www.researchgate.net/file.PostFileLoader.html?id...assetKey.

Gillies MT \& De Meillon B. The anophelinae of Africa south of the Sahara (Ethiopian zoogeographical region). The Anophelinae of Africa south of the Sahara (Ethiopian Zoogeographical Region). https://www.cabdirect.org/cabdirect/abstract/19692900946 
31. Scott JA, Brogdon WG, Collins FH. Identification of single specimens of the Anopheles gambiae complex by the polymerase chain reaction. Am J Trop Med Hyg, 1993; 49: 520-529. https://www.ncbi.nlm.nih.gov/pubmed/8214283 DOI: 10.4269/ajtmh.1993.49.520

32. Fanello C, Santolamazza F, Della Torre A. Simultaneous identification of species and molecular forms of the Anopheles gambiae complex by PCR - RFLP. Medical and veterinary entomology, 2002; 16(4), 461-464.

https://onlinelibrary.wiley.com/doi/abs/10.1046/j.1365-2915.2002.00393.x

33. Oringanje $\mathrm{C}$, Alaribe AA, Oduola AO, Oduwole OA, Adeogun AO, Meremikwu $\mathrm{MM}$, et al. Vector abundance and species composition of Anopheles mosquito in Calabar, Nigeria. Journal of Vector Borne Diseases, 2011; 48, pp. 171- 173. https://www.ncbi.nlm.nih.gov/pubmed/21946718

34. Paaijmans KP, Wandago MO, Githeko AK, Takken W. Unexpected high losses of Anopheles gambiae larvae due to rainfall. PLoS One, 2007; 2(11), e1146. https://doi.org/10.1371/journal.pone.0001146

35. Da DF, Diabaté A., Mouline K., Lefèvre T, Awono HP, Ouédraogo JB, Dabiré KR. Anopheles Rufipes remains a Potential Malaria Vector after the First Detection of Infected Specimens in 1960 in Burkina Faso. Journal of Infectious Diseases \& Therapy,2013; 1: 112. DOI:10.4172/2332-0877.1000112

36. Fahmy NT, Villinski JT, Bolay F, Stoops CA, Tageldin RA, Fakoli L, et al. The Seasonality and Ecology of the Anopheles gambiae complex (Dipetra: Culicidae) in Liberia Using Molecular Identification. Journal of medical entomology. 2015; 16;52(3):475-82. https://academic.oup.com/jme/article/52/3/475/1006726

37. Paupy C, Makanga B, Ollomo B, Rahola N, Durand P, Magnus J, et al. Anopheles moucheti and Anopheles vinckei are candidate vectors of ape Plasmodium parasites, including Plasmodium praefalciparum in Gabon. PloS one, 2013; 8(2), e57294. https://doi.org/10.1371/journal.pone.0057294 
38. Simard F, Ayala D, Kamdem GC, Pombi M, Etouna J, Ose K, et al. Ecological niche partitioning between Anopheles gambiae molecular forms in Cameroon: the ecological side of speciation. BMC Ecology.2009; 9:17.

https://bmcecol.biomedcentral.com/articles/10.1186/1472-6785-9-17

39. Thomsen EK, Koimbu G, Pulford J, Jamea-Maiasa S, Ura Y, Keven JB, et al. Mosquito behavior change after distribution of bednets results in decreased protection against malaria exposure. The Journal of infectious diseases. 2016; 22;215 (5):790-7. https://doi.org/10.1093/infdis/jiw615

40. Reddy MR., Overgaard HJ, Abaga S, Reddy VP, Caccone A, Kiszewski AE, et al. Outdoor host seeking behaviour of Anopheles gambiae mosquitoes following initiation of malaria vector control on Bioko Island, Equatorial Guinea. Malaria Journal, 2011; 10(1), 184. doi: 10.1186/1475-2875-10-184. https://doi.org/10.1186/1475-2875-10-184

41. Emergencies preparedness, response. Yellow fever - Nigeria: Disease outbreak news Retrieved 15 August 2018, 2018, from http://www.who.int/csr/don/22-december2017-yellow-fever-nigeria/en/

42. Ekanem IA, Alaribe AAA, Ekanem AP. Prevalence of Bancroftian Filariasis among Edim Otop sub-urban dwellers in Calabar Municipality of cross river state, Nigeria. Journal of Applied Pharmaceutical Science, 2011 1(9), 63.

43. Iboh Cl, Okon OE, Opara KN, Asor JE, Etim SE. Lymphatic filariasis among the Yakurr people of Cross River State, Nigeria. Parasites \& Vectors, 2012; 5, 203-203. doi: 10.1186/1756-3305-5-203. https://doi.org/10.1186/1756-3305-5-203

44. Udoidung NI, Braide El, Opara KN, Atting IA, Adie HA. Current status of bancroftian filariasis in rural communities of the lower cross river basin, Nigeria: parasitological and clinical aspects. Journal of Public Health, 2008; 16(6), 383. doi: 10.1007/s10389-008-0189-6. https://link.springer.com/article/10.1007/s10389-0080189-6 
bioRxiv preprint doi: https://doi.org/10.1101/805085; this version posted October 16,2019 . The copyright holder for this preprint (which was not certified by peer review) is the author/funder, who has granted bioRxiv a license to display the preprint in perpetuity. It is made available under aCC-BY-NC-ND 4.0 International license.

45. Sabbatani S, Fiorino S, Manfredi R. Plasmodium knowlesi: from Malaysia, a novel health care threat. Infez Med. 2012; 20(1):5-11.

https:// www.infezmed.it/index.php/article?Anno $=2012 \&$ numero $=1 \&$ ArticoloDaVisualizzare $=V 0$ l 201

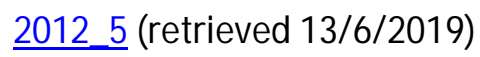


bioRxiv preprint doi: https://doi.org/10.1101/805085; this version posted October 16,2019 . The copyright holder for this preprint (which was not certified by peer review) is the author/funder, who has granted bioRxiv a license to display the preprint in perpetuity. It is made available under aCC-BY-NC-ND 4.0 International license.

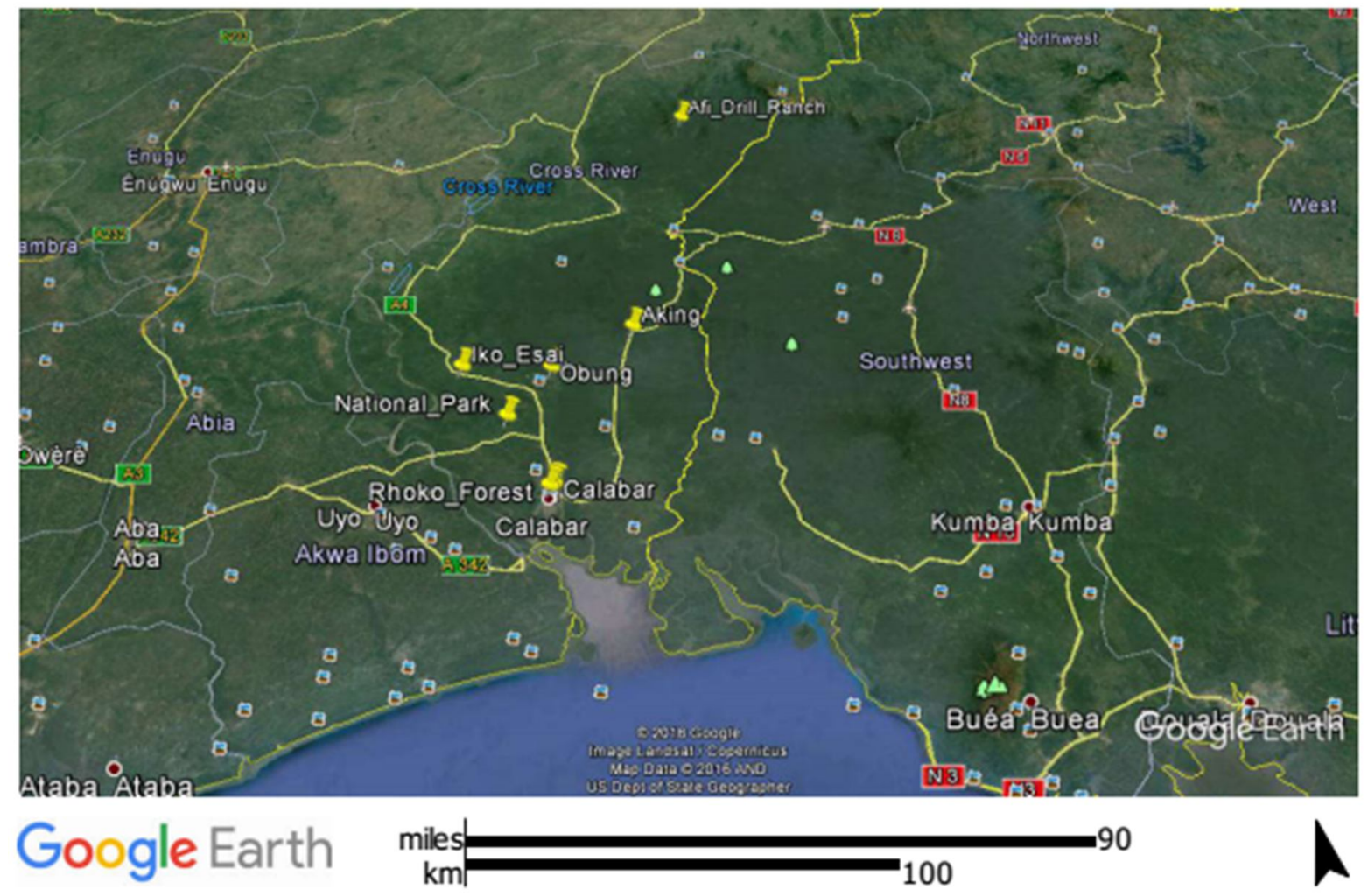

Figure1: Geographic Positioning System (GPS) of Study Location

\section{Sample collection}




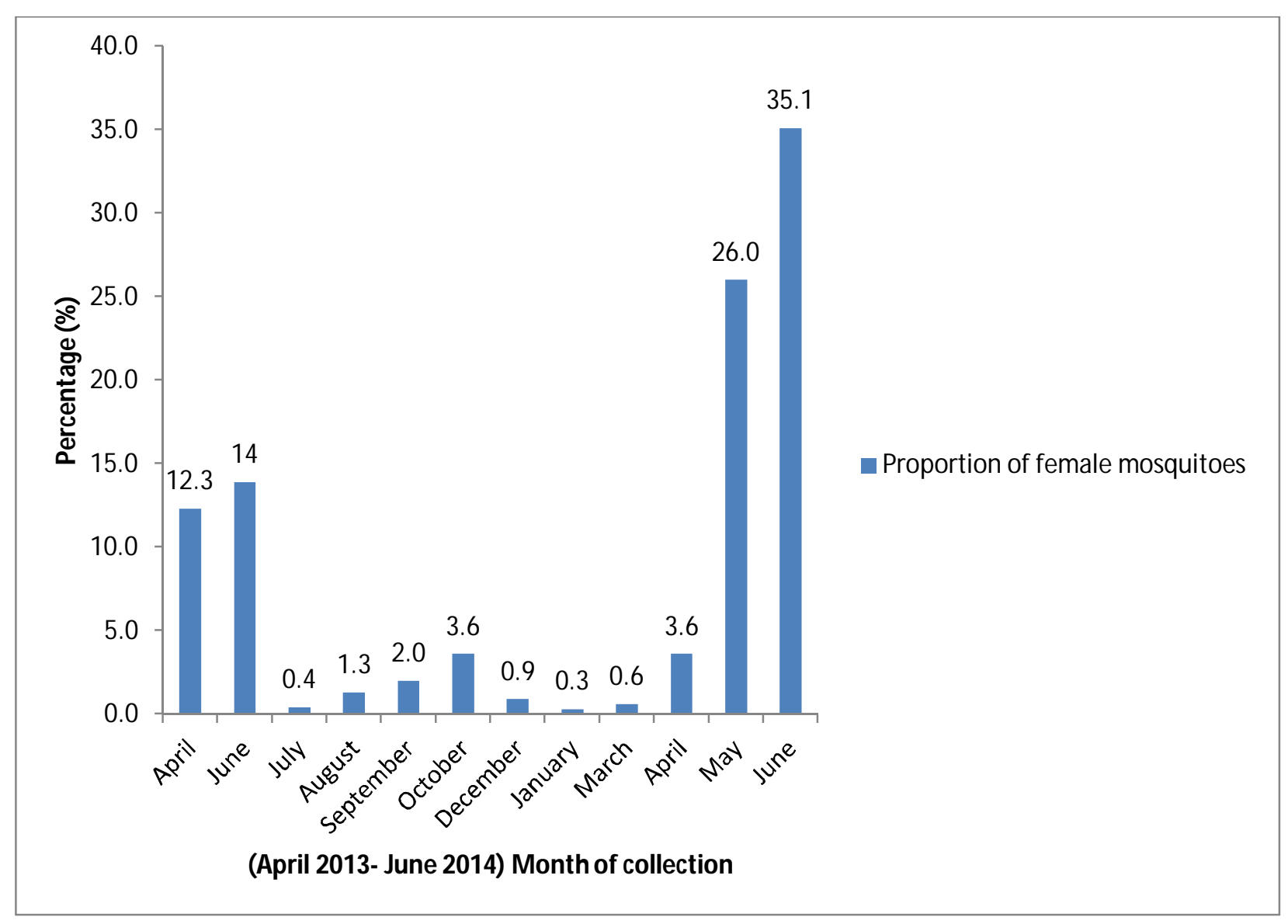

Figure 2: Distribution of female mosquitoes trapped by months of collection 
bioRxiv preprint doi: https://doi.org/10.1101/805085; this version posted October 16, 2019. The copyright holder for this preprint (which was not certified by peer review) is the author/funder, who has granted bioRxiv a license to display the preprint in perpetuity. It is made available under aCC-BY-NC-ND 4.0 International license.

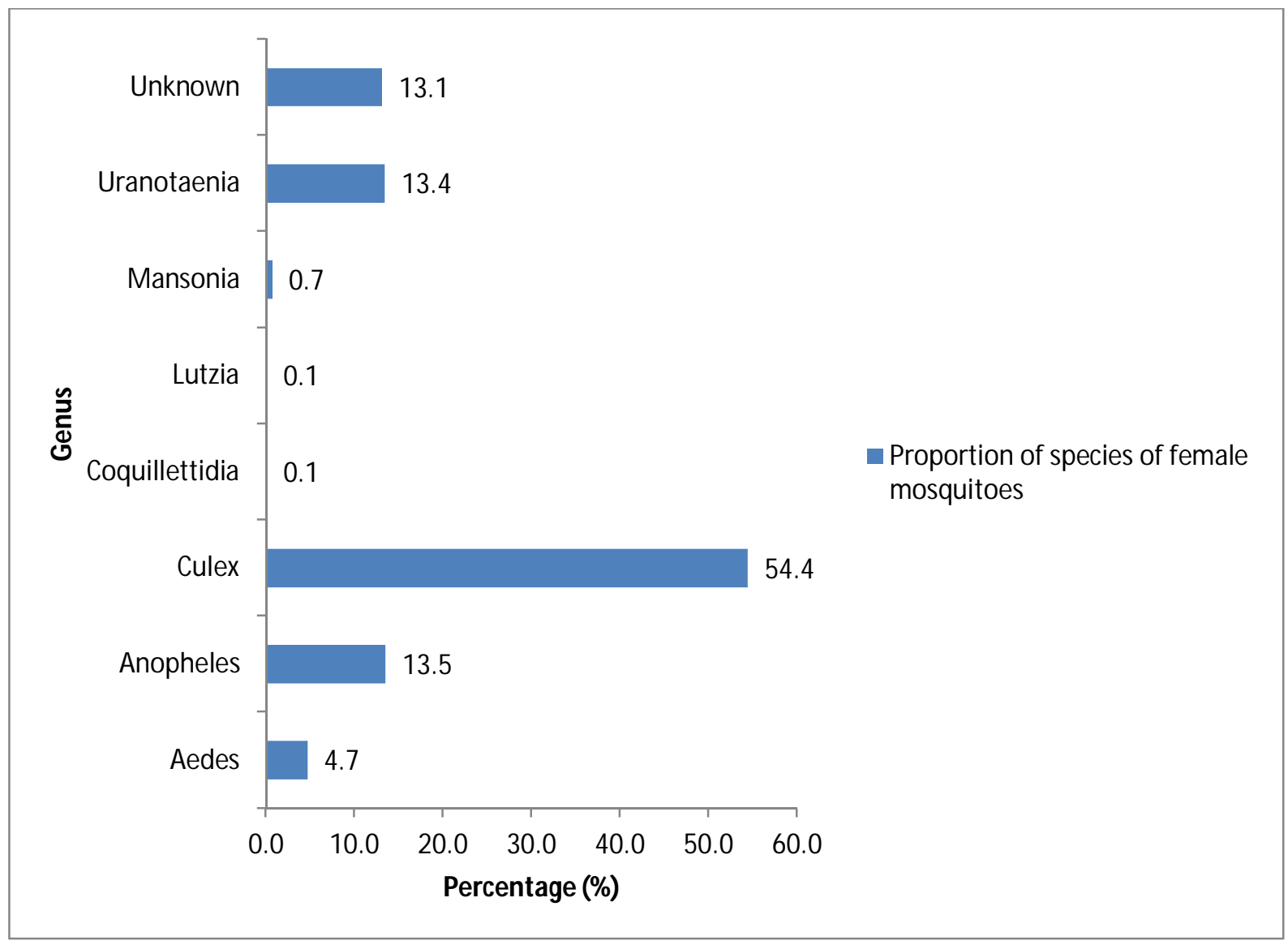

Figure 3(a): Proportion of female mosquitoes caught 


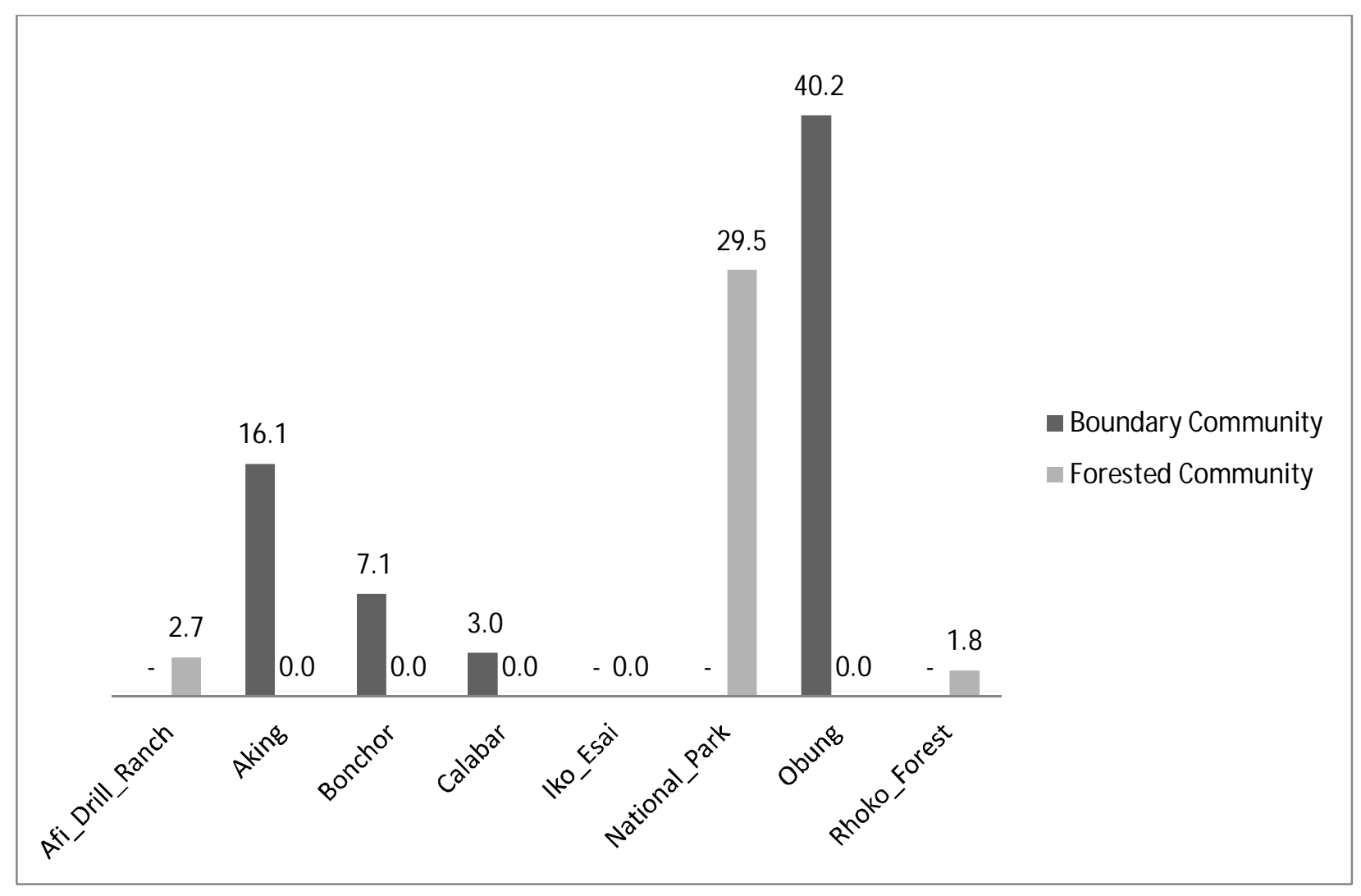

Figure 3(b): Proportion of female Anopheles mosquitoes per study site 


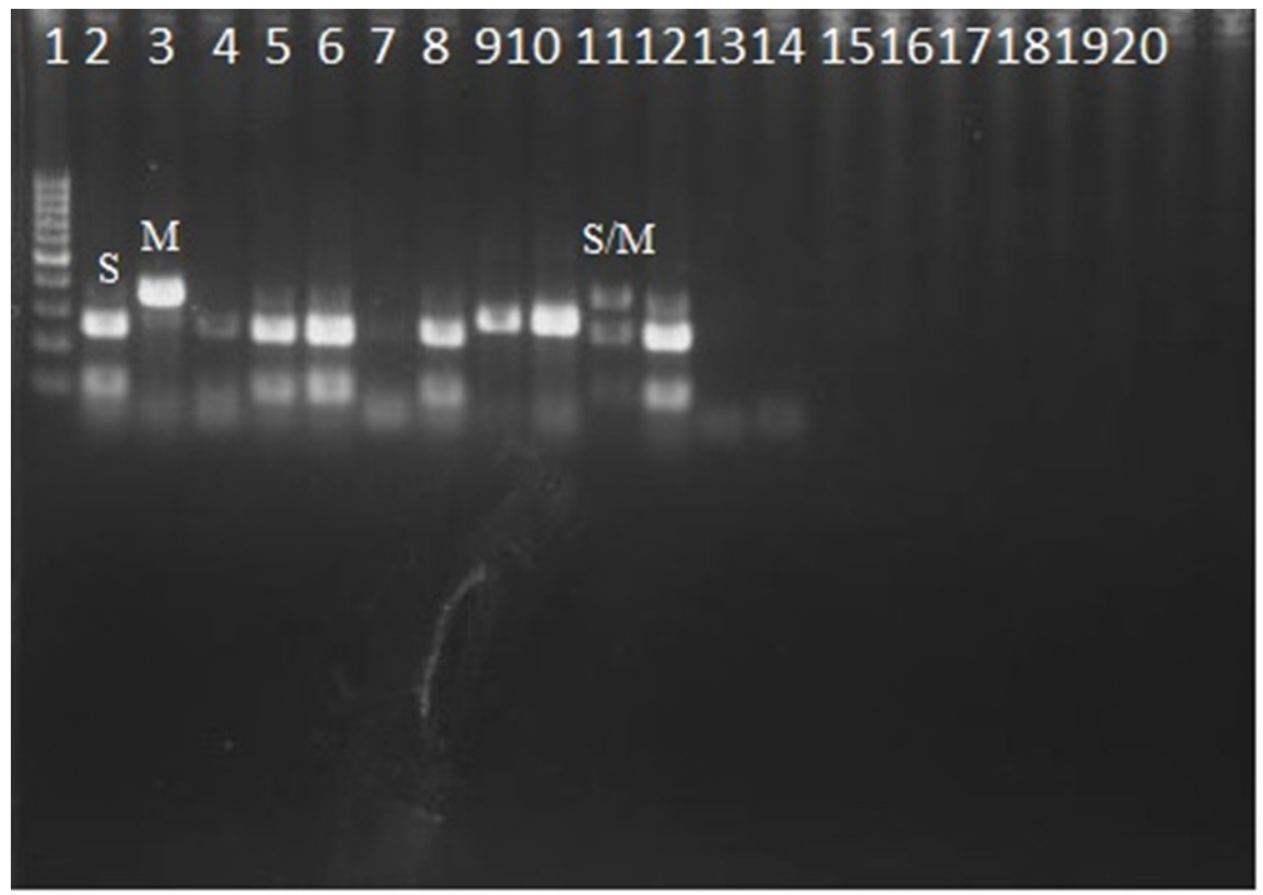

PCR-RFLP gel picture for molecular forms detection: Lanes $1=100 \mathrm{bp}$ ladder size standard; Lane 2, 4, 5,6,7,8,11 = A. gambiae S-Form; Lane 3, 9, $10=A$. gambiae MForm; Lane $11=\mathrm{M} / \mathrm{S}$ hyprid. Lane $15-20=$ No sample.

Figure 4: Molecular identification of A.gambiae s.s. and A.coluzzii using RFLP 